\title{
The Role of Women in Food Production and Poverty Reduction in Rural Communities in Cross River State
}

\author{
Judith Otu \\ Department of Sociology \\ University of Calabar \\ Bassey Anam \\ Institute of Public Policy \& Administration, \\ University of Calabar
}

\begin{abstract}
Women play significant roles in the development of the rural economy. The study examines their role in food production and poverty reduction in rural communities in Cross River State. The research design adopted for the study was survey research design. The population comprised of Agricultural extension workers and rural farmers in the southern senatorial district of Cross River State. The local government areas used in the study included, Akpabuyo, Bakassi, Calabar Municipality, Calabar South, Akamkpa and Odukpani. A sample population of 360 was systematically drawn from the sample area. Data obtained was analyzed using Mean and standard deviations. The result obtained showed that access to land, capital, and equipments significantly impacts on the level of food production and poverty reduction by rural women. Also, access to primary health care services significantly impacts on the level of food production and poverty reduction by rural women. Based on this conclusion, the study recommends the need to improve access to land and other economic resources so as to enhance the productive capacity of rural women.
\end{abstract}

Keywords: Women, Food Production, Poverty Reduction \& Rural Communities

\section{BACKGROUND TO THE STUDY}

Women play significant roles in the development of the rural economy. Scholars have come to terms with the fact that giving women an equal say in decision-making processes in rural development institutions improve their access to resources, factors of production such as land and capital, and to markets. Sessay and Odebiyi (1998) found that rural Nigerian women play an important role in food production and nutrition of their families with the women providing up to $80 \%$ of the food crops but the United Nations Development Programme (UNDP) (1997) has found that these rural women faced much constraints. Anyakoha and Mbanefoh (2000) found that these rural women who face enormous challenges and constraints in their role as providers of household nutrition security are under-rewarded resulting in poverty, environmental degradation, lack of appropriate technology, education and health (Imonikebe, 2010).

UNDP (1997) observed that poverty has been a longstanding issue in rural areas and Olayemi (2002) remarked that poverty in Nigeria has been described as an essential rural phenomenon because a disproportionately high percentage of the poor live in rural areas. Anyakoha et al (1997) reported that technological supports are male-oriented and gender biased. They emphasized that such technological support by government cannot promote women's contribution in household nutrition security. 
For agricultural growth to reach its potential, gender disparities must be addressed and effectively reduced. FAO (2011) estimates that closing the gender gap in agriculture would generate significant gains for the agricultural sector: If women had the same access to productive resources as men, they could increase yields on their farms by $20-30 \%$. This, in turn, could raise total agricultural output in developing countries by up to $4 \%$, potentially reducing the number of hungry people by 100-150 million.

Rural women, the majority of whom depend on natural resources and agriculture for their livelihoods, (World Bank, 2010), make up over a quarter of the total world population (FAO, 2000). In developing countries, rural women represent approximately 43 per cent of the agricultural labour force, (FAO, 2011) and produce, process and prepare much of the food available, thereby giving them primary responsibility for food security. Bearing in mind that 76 per cent of the extreme poor live in rural areas (World Bank and IMF (2013), ensuring rural women's access to productive agricultural resources empowers women and contributes to decreasing world hunger and poverty (FAO, 2011).

However, there are factors which affect the abilities of rural women to perform at their maximum. Many rural women farmers have poor health status. This could be due to heavy farm work, childbearing and rearing and poor nutrition. The rural areas in Nigeria do not have good roads and social amenities such as potable water, health care services and electricity. Anyakoha and Mbanefoh (2002) stated that where there were no motorable roads, women trek very long distance and this usually wore and tore the women down gradually. Mbanefoh (1994) observed that rural households do not often have enough to meet their basic needs. As such they spend $80 \%$ of their income on food leaving little on housing, health and education. Anyakoha and Mbanefoh (2000) concluded that the lives of poor rural households revolve round a continuous struggle for food and a continuous threat of seasonal food shortages or price increase which makes food hard to be obtained.

This paper seeks to examine the contributions of women in food production and poverty reduction in Cross River State. It will identify specific challenges facing these women the integrated strategies that will be significant in improving their present social and economic state.

\section{STATEMENT OF THE PROBLEM}

In developing countries, among the poor, rural women are the poorest and more vulnerable. Empirical evidences suggest that women in rural areas are more adversely affected by poverty than men (Daman, 2003). The incidence of poverty among rural women is on the rise in most of the developing countries. The issues of gender bias and equity point to the double burden women have to bear - that of being poor and being a woman. Further strategies and programmes for development had largely overlooked the question of gender equity. Projects aiming to reduce poverty view the poor rural women as the recipient of benefits of development, instead of active participant and still poor rural women have the least access to basic needs such as food, health and education (Daman, 2003).

At least $70 \%$ of the world's very poor people live in rural areas in developing countries (IFAD 2011). Their livelihoods usually depend either directly or indirectly on agriculture, with women providing, on average, more than $40 \%$ of the agricultural labor force. This female labor ration ranges from approximately $20 \%$ in Latin America to $50 \%$ in Eastern Asia and SubSahara Africa (FAO 2011). In Nigeria, the women population in the rural communities provides 
most of the needed labour in food production. Notwithstanding, they are the most vulnerable to related health challenges and poor economic life (Anam, 2014).

Again, food production remains insufficient to the growing Nigerian population because most of these rural women do not work with modern farming equipments. On this note, this study seeks to answer the following questions,

1. Does access to land, capital, equipments have any significant impact on the level of food production and poverty reduction by rural women?

2. Does access to primary health care services have any significant impact on the level of food production and poverty reduction by rural women?

\section{OBJECTIVE OF THE STUDY}

The paper seeks to examine the role of women in food production and poverty reduction in rural communities in Cross River State. It will identify specific challenges faced by the women and further highlight useful recommendations that will be significant in improving their capacity.

\section{METHOD AND SOURCE OF DATA}

Survey research design was used to examine the role of women in food production and poverty reduction in Cross River State. The population comprised of Agricultural extension workers and rural farmers in the southern senatorial district of Cross River State. The local government areas used in the study included, Akpabuyo, Bakassi, Calabar Municipality, Calabar South, Akamkpa and Odukpani. A sample population of 360 was systematically drawn from the sample area. Questionnaire was used for data collection. It had a 4-point scale of strongly agree, agree, disagree, strongly disagree representing 4, 3, 2 and 1 respectively. The copies of the questionnaire were administered to the respondents by the researchers and research assistants.

They were retrieved immediately after completion on the same day. The responses to each of the questionnaire items were arranged in frequency distribution tables and percentages mean responses, and standard deviation of the items were computed and the results clearly stated and discussed.

\section{LITERATURE AND THEORETICAL FRAMEWORK}

Traditionally, and especially in the African setting and other developing countries, women are primarily responsible to meet the basic needs of their families. Women mainly produce food for household consumption and local markets, whereas men more often work in agricultural wage labor and cash crop production (Anam, 2014). Generally, women are responsible for food selection and preparation, and for the care and feeding of the children, and therefore play a key role in defining the coping strategies of poor households to ensure food security and to reduce risk. Women normally spend a higher share of their income than men on providing food, health and education to the family. Additionally, they expend a lot of time and hard work in procuring water and domestic fuel.

For instance, in Lesotho women spend more than twice as much time as men and boys in fetching water and gathering firewood. Alongside the above described responsibility for reproductive tasks, women are also engaged in productive tasks such as agricultural work, raising cattle, seed management, planting, as well as the processing and marketing of agricultural products. In livestock farming, women feed the animals, clean the stalls and 
compost manure. When raising poultry, sheep, goats or rabbits, they are responsible for breeding and tending to the animals' health. It is women who cultivate the kitchen gardens, and who sustain the family when harvests are poor.

However, in most African traditional societies, women have been regarded as fragile and should be subordinate to the man but they can play very important role for the betterment of the society. Across the country, women create innovative, comprehensive programs to meet the needs of their communities. Women have established themselves as leaders in the community development process and acquire the skills that have brought positive changes to their communities. As effective builders of social capital, women leaders play key roles in establishing and maintaining important relationships and networks in their communities.

Women are often faced with challenges of racial, culture, economic and political barriers that exist in the community development process and in many cases overcoming those barriers becomes their motivation. While their comprehensive approach has influenced the evolution of the community development field, women's contributions have been neither widely acknowledged nor explicitly credited. Studies that examine the role of women associations in development provide deeper insights into women's thinking about community development, the barriers they perceive to women's leadership and the kind of efforts that should be made to facilitate and promote their status and roles in the field (Kalu, 2006 \& Chinendu, 2008).

The activities performed by women are often unpaid. War, disease, HIV/AIDS and the migration of male family members to urban areas or foreign countries are forcing more and more women to take on additional roles that were originally performed by men, with many assuming sole responsibility for agricultural production. Given the importance and variety of their tasks, women are important bearers of knowledge related to the sustainable use of natural resources, including strategies for adapting to climate change and conserving agrobiodiversity (Ditcher, 1992).

In addition, women have limited access to natural resources. Women's access to agricultural land and the use of natural resources such as water or trees is dependent on the rights of husbands or male kin. Inheritance laws continue to be religiously based. Muslim women are entitled to inherit from their father half the share of their brothers as a form of insurance against marital breakdown and to ensure visits to the parental home. These factors seriously cripple women's capacity to effectively contribute to community development (Momen and Begun, 2006).

Zeller and Meyer (2002) acknowledge that one of the strategies adopted by women in generating income is by daily and monthly contributions. This is done at their association level. When this money accumulates, they convert it into business by giving it out as credit facilities or loan. Sustainable credit facilities create new opportunities to save and invest in income activities, and help individuals or households to build up or acquire funds for all kinds of investments (Zeller \& Meyer, 2002). In most cases, these contributions and issuing of credit facilities leads to the establishment of micro finance banks.

Most rural women do not have access to good medical health services (Anam, 2014). They are exposed to a lot of poor sanitary conditions. Inadequate access to safe water and sanitation leads to various health problems of people. Water and vector-borne disease like diarrhea, dysentery, typhoid, worm infestation, polio, malaria, hepatitis and other parasitic infections are 
too common in Nigeria and cause numerous deaths. In rural areas, about 69,000 children below the age of five die of diarrhea every year because of inadequate sanitation (HO, 2990), which is easily preventable by improving sanitation and creating awareness to practice hygiene such as simple hand washing, with soap GoB, UNICEF and ICDDRB (2008) reported that less than $1 \%$ of Bangladeshis wash their hands with soap before they eat and fewer than $17 \%$ wash their hands with soap or ash after defection.

According to WHO and UNICEF (2006), about $22 \%$ of the population of the country is still exposed to drinking water which does not comply with WHO standards. On the other hand, surface water is usually polluted and requires treatment. Many parts of the country have arsenic contamination in the ground water (UNICEF, 2006; UNDP, 2000). Still the government claims that about $90 \%$ of people have access to safe water (BBS 2008). The place of sound health cannot be underestimated when discussing issues of effective food production and poverty reduction.

However, in spite of their important and diverse contributions, women in agriculture and rural areas have less access than men to productive resources. Gender inequality is present in many assets, inputs and services: e.g. access to or control over land, financial services, productive resources, and extension or marketing services. For example, men represent $85 \%$ of agricultural landholders in Sub-Sahara Africa. In Ghana, Madagascar and Nigeria men own more than twice the units of livestock compared to women. Similar gaps exist in access to fertilizer, mechanical equipment, new technologies, extension services and credit (UNDP 2012).

Several studies have shown that gender inequality related to food security is exacerbated during crises: Women tend to become the "shock absorbers" of household food security, e.g. skipping meals, to make more food available for other household members. Moreover, women are often underrepresented in rural organizations and institutions, and are generally poorly informed regarding their rights. This prevents them from having an equal say in decisionmaking processes, and reduces their ability to participate in collective activities, e.g. as members of agricultural cooperatives or water user associations. Due to the above factors, among others, female farmers produce less than male farmers. This situation imposes costs on the agriculture sector, the broader economy and society, as well as on women themselves. Gender inequalities result in less food being grown, less income being earned, and higher levels of poverty and food insecurity.

Gender equality is clearly recognized as a human right on an international level. Over the past several years, UN member states have entered into a number of commitments. The Rome Declaration on Food Security, resulting from the FAO World Food Summit in 1996, affirms the obligation to promote the equal rights and duties of men and women regarding food security. The Millennium Development Goals underline the fact that, without gender equality, it will be impossible to reduce by half the number of people who suffer from hunger by 2015 (Khan \& Rahaman, 2014). Regardless of the level of development achieved by the respective economies, women play a pivotal role in food production and in rural development in most countries and in Nigeria in particular.

\section{THEORETICAL FRAMEWORK}

The sustainable livelihood approach is used in this study. The concept was first introduced by the Brudtland Commission on environment and development as a way of linking socioeconomic and ecological considerations in a cohesive, policy relevant structure. The 1992 
United Nations Conference on Environment and Development (UNCED) expanded the concept, especially in the context of Agenda 21, and advocated for the achievement of sustainable livelihoods as a broad goal for poverty eradication. It stated that sustainable livelihoods could serve as an integrating factor that allows policies to address development, sustainable resource management, and poverty eradication simultaneously (UNDP, 1997). Livelihoods are studied and analyzed because these provide holistic information that can reveal how, and why, people survive (or fail to survive) difficult times so as to reduce vulnerability. Many development agencies have adopted the livelihood concept as central to their development strategies and activities with further minor modifications (Gupta 1992). Most of the discussion on sustainable livelihood so far has focused on rural areas and situations where people are farmers or make a living from some kind of primary self-managed production.

Within the context of women contribution to community development, the approach significantly explains the maintenance or enhancement of resource productivity on a long term basis. The concept of "sustainable rural livelihoods" is increasingly central to the debate about rural development, poverty reduction and environmental management. The livelihood approach is founded on a belief that people. Especially rural women require a range of assets to achieve positive livelihood outcomes. The ability to move out of poverty is critically dependent on access to assets (Warner 2006) and this explains the need to improve the capacity of rural women to enhance improve food production and poverty reduction in their communities and country at large. Access to resources indicates that individuals, household or groups are able to use these, and access gives them capability to build their livelihood (Bebbington, 1999).

\section{RESULTS AND DISCUSSIONS}

Two research questions were stated to guide this study. Data were obtained with the aid of a research questionnaire administered to rural women across the State. Data obtained were analyzed using Mean and standard deviations. The result is as shown below,

\section{RESEARCH QUESTION ONE}

Does access to land, capital, equipment have any significant impact on the level of food production and poverty reduction by rural women?

Table 1: Mean and standard deviations of access to land, capital, equipment and its significant impact on the level of food production and poverty reduction by rural women

\begin{tabular}{lccc}
\hline VARIABLE & MEAN & STD. D. & N \\
\hline LAND, CAPITAL, EQUIPMENT & 17.99 & 1.41 & 360 \\
LEVEL OF FOOD PRODUCTION & & & \\
AND POVERTY REDUCTION & 18.01 & 1.26 & 360 \\
\hline
\end{tabular}

The table indicates a significant relationship between access to land, capital, equipment and the level of food production and poverty reduction by rural women. The implication is that access to land, capital; equipment by rural women in Cross River State has a significant impact on the level of food production and poverty reduction. Upon this result, concerted efforts must be made by the government to increase their level of access to land so as to boost food production in the state and country at large. 


\section{RESEARCH QUESTION TWO}

Does access to primary health care services have any significant impact on their level of food production and poverty reduction by rural women?

Table 2: Mean and standard deviation of access to primary health care services and its impact on the level of food production and poverty reduction by rural women

\begin{tabular}{llccc}
\hline VARIABLE & MEAN & STD. D. & N \\
\hline $\begin{array}{l}\text { ACCESS TO PRIMARY } \\
\text { CARE SERVICES }\end{array}$ & 18.98 & 1.44 & 360 \\
$\begin{array}{l}\text { LEVEL OF FOOD PRODUCTION } \\
\text { AND POVERTY REDUCTION }\end{array}$ & 19.13 & 1.36 & 360 \\
\hline
\end{tabular}

The table indicates a significant relationship between access to primary health care services and the level of food production and poverty reduction by rural women. The implication is that when rural women have access to good medical attention, it will improve their capacity to perform. The government must therefore make concerted efforts in providing well equipped health centers in rural communities in the state and nation at large.

\section{CONCLUSION}

It is an obvious fact that majority of women in the rural areas in Nigeria are involved in food production. They face a lot of challenges and constraints, which adversely affect their level of food production. Some examples of such constraints are illiteracy, poverty, lack of application of appropriate technology. Capacity development is the key to improving women's performance, i.e. their knowledge of legal matters and their general education can substantially contribute to raising women's access to natural resources, means of production and improved access to health care delivery services.

To increase food production and compensate the effort of rural Nigerian women farmers it is the position of this paper that the health condition of rural women must be given due attention with easy access and affordable medical services. They must be provided with modern farm inputs. This will include adequate use of fertilizers, pesticides, insecticides, herbicides, improved skills of developed countries, provision of infrastructural facilities, transport/communication networks, and storage facilities to improve the marketing system. In addition there must be application of appropriate technology in food preservation. This can be achieved through the use of extension workers to train and retrain rural farmers on modern technology.

Imonikebe (2010) noted strongly that technology alone does not make a change. Not all new technologies save time or empower rural women. In fact, some technologies add to women's burdens by making tasks more demanding (e.g. extra weeding required when fertilizer is used, or the need to process more output). The mere introduction of a new technology alone is not able to simultaneously boost agricultural yields and reduce ingrained gender biases, since relationships between women and men are dynamic and complex. Men often move in and take over when a new technology results in a more profitable crop or when a new processing machine increases income. Policies thus need a gender perspective to ensure that technologies are developed and applied in ways that prevent an automatic takeover of the technology by men. 
The study recommends as follows,

\section{RECOMMENDATIONS}

1. The need to uincrease access to land, capital, equipment so as to improve the level of food production and poverty reduction by rural women in rural communities

2. Improve access to primary health care service delivery in rural communities. Improved health status of rural women will mean improved agricultural activities

3. Provision of literacy programmes for rural women. Improved literacy level will guarantee enhanced capacity and social economic development of the rural economy.

4. Encourage mechanized farming system in rural areas. This will require providing rural farmers with enabling farm equipments and training them on how to use the equipments.

5. There is also need to provide farm subsidies to farmers. This will improve their productivity. An enabling marketing policy by the government will not only encourage production but further improve socio economic activities within the rural economy.

\section{References}

Anam, B. (2014), Understanding community \& rural development. Calabar: Ethereal Bliss

Anyakoha, E. U. \& Mama, R. O (1997), Appropriate technology utilization by rural women in Nigeria. Obstacle enhancement strategies and implications for technology policy: research report Kenya African technology policy studies network (ATPS).

Anyakoha, E. U. \& Mbanefoh, E. (2002), Nigerian women and household nutrition security in the new millennium: challenges and enhancement strategies. Journal of Home Economics Research Vol. iv.

Anyakoha, O. S. \& Mbanefoh, C. (2000), Pricing efficiency. London: University of London P. 30.

Bebbinton, K. (1999), Issues and perspectives in sustainable agricultural and rural development. Main document No. 1 at the FAO/Netherlands Conference on Agriculture and the Environment held in Hertogenbosch, Netherlands, 15-19 April.

Daman, P. (2003), Rural women, food security and agricultural cooperatives. ICA-Japan Agricoops Management Training Project for Asia. http://www.uwcc.wisc.edu/info/intl/rur_women.pdf

FAO (2011), The State of food and agriculture Report 2010-2011: women in agriculture: Closing the gender gap for development".

IFAD (2011), Rural poverty report.

Imonikebe, B. U. (2010), Constraints to Rural women farmers' involvement in food production in Nigeria. International Multi-Disciplinary Journal, Ethiopia. .4 (3b) July,

Kalu, S. \& Chinendu, K. (2008), "Food security and African economy. Zaria Ojo press.

Khan, C. \& Rahanman (2014), "Decolonizing agricultural information. Paper prepared for FAO RAPA, Bangkok. London; New York

Mbanefoh N. (1994), "Impacts of better life Programme. oil palm processing technology on drudgery and income levels of rural women in Nigeria. Enugu: University of Nuskka press.

Momen, k. \& Begun, D. (2006), Strategies for rural development. London: Macmillan Press.

Olalayemi J. (2002), Nigeria government policy declaration on Poverty alleviation in relation to agriculture. A paper presented at the fourth APPAN policy workshop held at the international institute of tropical agriculture (IITA) Ibadan: Nigeria June.

Sassay \& Odebiyi (1998), Economics development: implications for home economics education. London: Macmillan Press.

The World Bank, Gender and governance in rural services. 1, DOI: 10.1596/978-0-8213-7658-4, (February 1, 2010), http://siteresources.worldbank.org/INTARD/Resources/gender_and_gov_in_rural_services.pdf.

UNDP (2012), Africa human development report 2012. towards a food secure future Ibadan: Oyo. 
Otu, J. \& Anam, B. (2016). The Role of Women in Food Production and Poverty Reduction in Rural communities in Cross River State. Advances in Social Sciences Research Journal, 3(9) 56-64.

United Nations Development (UNDP) (1997), Nigerian human development Report 1996. Lagos: UNDP.

Warner, K. (2006), The State of Food and Agriculture: Women in Agriculture: Closing the Gender Gap for Development. http://www.fao.org/docrep/013/i2050e/i2082e00.pdf.

World Bank and IMF (2013), Global monitoring report 2013: rural-urban dynamics and the millennium development goals.

Zeller B. \& Meyer, O. (2002), Human development report. New York: United Nations development programme. 